Pacific Journal of Mathematics

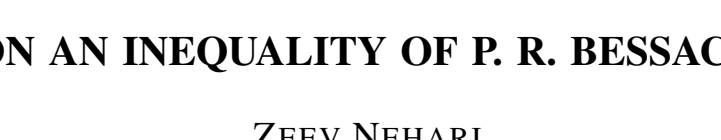




\section{ON AN INEQUALITY OF P. R. BEESACK}

\section{ZeEV NeHARI}

In a recent paper [1], P. R. Beesack derived the inequality

$$
|g(x, s)| \leqq \frac{\prod_{\nu=1}^{n}\left|x-a_{\nu}\right|}{\left(a_{n}-a_{1}\right)(n-1) !}
$$

for the Green's function $g(x, s)$ of the differential system

$$
\begin{gathered}
y^{(n)}=0, \quad y\left(a_{\nu}\right)=0, \quad \nu=1,2, \cdots, n, \\
-\infty<a_{1}<a_{2}<\cdots<a_{n}<\infty .
\end{gathered}
$$

In addition to being interesting in its own right, this inequality is a useful tool in the study of the oscillatory behavior of $n$th order differential equations. It would therefore appear to be worth while to give a short proof of (1). The derivation of this inequality in [1] is rather complicated.

We denote by $\left[x_{0}, x_{1}, \cdots, x_{k}\right]$ the $k$ th difference quotient of the function $g(x)=g(x, s)$, i.e., we set

$$
\begin{gathered}
{\left[x_{0}, x_{1}\right]=\frac{g\left(x_{0}\right)-g\left(x_{1}\right)}{x_{0}-x_{1}},} \\
{\left[x_{0}, x_{1}, \cdots, x_{\nu}\right]=\frac{\left[x_{0}, x_{1}, \cdots, x_{\nu-1}\right]-\left[x_{1}, x_{2}, \cdots, x_{\nu}\right]}{x_{0}-x_{\nu}}, \quad \nu=2, \cdots .}
\end{gathered}
$$

This difference quotient can also be represented in the form

$$
\left[x_{0}, \cdots, x_{k}\right]=\int \cdots \int g^{(k)}\left(t_{0} x_{0}+t_{1} x_{1}+\cdots+t_{k} x_{k}\right) d t_{0} d t_{1} \cdots d t_{k-1},
$$

where the integration is to be extended over all the positive values of the $t_{\nu}$ for which

$$
t_{0}+t_{1}+\cdots+t_{k}=1 \text {. }
$$

This formula, which goes back to Hermite, is easily verified by induction (cf., e.g., [2]). It holds if $g(x)$ has continuous derivatives up to the order $k-1$, and if $g^{(k)}$ is piecewise continuous.

Since, by its definition, $g(x, s)$ has continuous derivatives up to the order $n-2$, while $g^{(n-1)}$ has the jump

$$
g_{+}^{(n-1)}(s)-g_{-}^{(n-1)}(s)=-1
$$

Received April 11, 1963. This research was supported by the United States Air Force Office of Scientific Research. 
at $x=s$, we may apply (3) with $k=n-1$. We shall do so twice, identifying the points $x_{0}, \cdots, x_{n-1}$ with $x, a_{1}, \cdots, a_{n-1}$ and $x, a_{2}, \cdots, a_{n}$, respectively. Since, because of $g\left(a_{\nu}, s\right)=0, \nu=1, \cdots, n$, we have

$$
\left[x, a_{1}, \cdots, a_{n-1}\right]=\frac{g(x, s)}{\prod_{\nu=1}^{n-1}\left(x-a_{\nu}\right)}
$$

and

$$
\left[x, a_{2}, \cdots, a_{n}\right]=\frac{g(x, s)}{\prod_{\nu=2}^{n}\left(x-a_{\nu}\right)},
$$

we obtain, upon subtracting these expressions from each other,

$$
\frac{\left(a_{n}-a_{1}\right) g(x, s)}{\prod_{\nu=1}^{n}\left(x-a_{\nu}\right)}=\int_{D} g^{(n-1)}(v) d t-\int_{D} g^{(n-1)}(u) d t,
$$

where, for brevity, $d t=d t_{0} d t_{1} \cdots d t_{n-2}, D$ denotes the region defined by (4) (with $k=n-1$ and $t_{\nu}>0, \nu=0, \cdots, n-1$ ), and

$$
u=t_{0} x+t_{1} a_{1}+\cdots+t_{n-1} a_{n-1}, v=t_{0} x+t_{1} a_{2}+\cdots+t_{n-1} a_{n} .
$$

Both for $a_{1} \leqq x<s$ and $s<x \leqq a_{n}, g(x, s)$ is a polynomial of degree $n-1$. Accordingly, the function $g^{(n-1)}(x, s)$ is capable only of two constant values, say $\alpha$ and $\beta$, which according to (5) are related by $\alpha=\beta+1$. If we denote by $D_{1}$ the subset of $D$ in which $a_{1} \leqq u<s$ (where $u$ is defined in (7), we have

$$
\begin{aligned}
\int_{D} g^{(n-1)}(u) d t & =\alpha \int_{D_{1}} d t+\beta \int_{D-D_{1}} d t=\alpha \int_{D_{1}} d t+(\alpha-1) \int_{D-D_{1}} d t \\
& =\alpha \int_{D} d t-\int_{D-D_{1}} d t
\end{aligned}
$$

Similarly,

$$
\int_{D} g^{(n-1)}(v) d t=\alpha \int_{D} d t-\int_{D-D_{2}} d t
$$

where $D_{2}$ is the subset of $D$ in which $a_{1} \leqq v<s$. Substituting these expressions in (6), we obtain

$$
\frac{\left(a_{n}-a_{1}\right) g(x, s)}{\prod_{\nu=1}^{n}\left(x-a_{\nu}\right)}=\int_{D-D_{2}} d t-\int_{D-D_{1}} d t .
$$

The differential $d t$ is positive, and we thus have

$$
-\int_{D} d t \leqq-\int_{D-D_{1}} d t \leqq \int_{D-D_{2}} d t-\int_{D-D_{1}} d t \leqq \int_{D-D_{2}} d t \leqq \int_{D} d t
$$


Since

$$
\int_{D} d t=\frac{1}{(n-1) !}
$$

(as can be seen be applying (3) to the function $x^{n-1}$ and setting $k=$ $n-1)$, this shows that

$$
\left|\int_{D-D_{2}} d t-\int_{D-D_{1}} d t\right| \leqq \frac{1}{(n-1) !}
$$

In view of (8), this establishes the inequality (1).

\section{REFERENCES}

1. P. R. Beesack, On the Green's function of an n-point boundary value problem, Pacific J. Math., 12 (1962), 801-812.

2. N. E. Nörlund, Lȩons sur les séries d'interpolation, Paris, Gauthier-Villars, 1926. CARNEGIE INSTITUTE OF TECHNOLOGY 



\section{PACIFIC JOURNAL OF MATHEMATICS}

\section{EDITORS}

Robert Osserman

Stanford University

Stanford, California

M. G. Arsove

University of Washington

Seattle 5 , Washington
J. DugundjI

University of Southern Califorma: Los Angeles 7, California

Lowell J. Paige

University of California

Los Angeles 24, California

\section{ASSOCIATE EDITORS}

E. F. BECKENBACH

B. H. NeumanN

F. WOLF

K. YosIDA

\section{SUPPORTING INSTITUTIONS}

UNIVERSITY OF BRITISH COLUMBIA

CALIFORNIA INSTITUTE OF TECHNOLOGY

UNIVERSITY OF CALIFORNIA

MONTANA STATE UNIVERSITY

UNIVERSITY OF NEVADA

NEW MEXICO STATE UNIVERSITY

OREGON STATE UNIVERSITY

UNIVERSITY OF OREGON

OSAKA UNIVERSITY

UNIVERSITY OF SOUTHERN CALIFORNIA
STANFORD UNIVERSITY

UNIVERSITY OF TOKYO

UNIVERSITY OF UTAH

WASHINGTON STATE UNIVERSITY

UNIVERSITY OF WASHINGTON

AMERICAN MATHEMATICAL SOCIETY CALIFORNIA RESEARCH CORPORATION SPACE TECHNOLOGY LABORATORIES NAVAL ORDNANCE TEST STATION 


\section{Pacific Journal of Mathematics}

\section{Vol. 14, No. 1 \\ May, 1964}

Richard Arens, Normal form for a Pfaffian .........................

Charles Vernon Coffman, Non-linear differential equations on cones in Banach

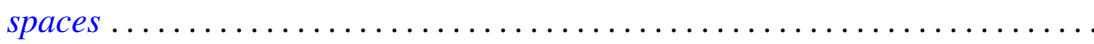

Ralph DeMarr, Order convergence in linear topological spaces ..............

Peter Larkin Duren, On the spectrum of a Toeplitz operator ................

Robert E. Edwards, Endomorphisms of function-spaces which leave stable all

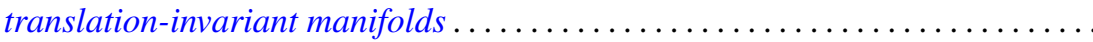

Erik Maurice Ellentuck, Infinite products of isols . . . . . . . . . . . . . . . . 49

William James Firey, Some applications of means of convex bodies . . . . . . . . 53

Haim Gaifman, Concerning measures on Boolean algebras ............. 61

Richard Carl Gilbert, Extremal spectral functions of a symmetric operator. . . . . . 75

Ronald Lewis Graham, On finite sums of reciprocals of distinct nth powers ..... 85

Hwa Suk Hahn, On the relative growth of differences of partition functions ...... 93

Isidore Isaac Hirschman, Jr., Extreme eigen values of Toeplitz forms associated

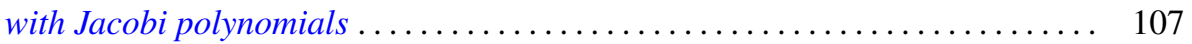

Chen-jung Hsu, Remarks on certain almost product spaces . . . . . . . . . . . 163

George Seth Innis, Jr., Some reproducing kernels for the unit disk . . . . . . . . . 177

Ronald Jacobowitz, Multiplicativity of the local Hilbert symbol . . . . . . . . . . . 187

Paul Joseph Kelly, On some mappings related to graphs ................. 191

William A. Kirk, On curvature of a metric space at a point . . . . . . . . . . . . 195

G. J. Kurowski, On the convergence of semi-discrete analytic functions . . . . . . . 199

Richard George Laatsch, Extensions of subadditive functions . . . . . . . . . . . 209

V. Marić, On some properties of solutions of $\Delta \psi+A\left(r^{2}\right) X \nabla \psi+C\left(r^{2}\right) \psi=0 \ldots 217$

William H. Mills, Polynomials with minimal value sets . . . . . . . . . . . 225

George James Minty, Jr., On the monotonicity of the gradient of a convex

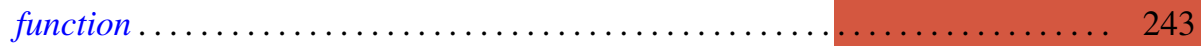

George James Minty, Jr., On the solvability of nonlinear functional equations of 'monotonic' type ................................... 249

J. B. Muskat, On the solvability of $x^{e} \equiv e(\bmod p) \ldots \ldots \ldots \ldots \ldots \ldots \ldots \ldots . \ldots \ldots$

Zeev Nehari, On an inequality of $P . R$. Bessack ................... 261

Raymond Moos Redheffer and Ernst Gabor Straus, Degenerate elliptic

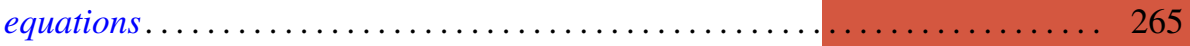

Abraham Robinson, On generalized limits and linear functionals . . . . . . . . . 269

Bernard W. Roos, On a class of singular second order differential equations with a

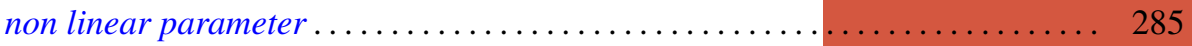

Tôru Saitô, Ordered completely regular semigroups . . . . . . . . . . . . . . . . 295

Edward Silverman, A problem of least area ....................... 309

Robert C. Sine, Spectral decomposition of a class of operators . . . . . . . . . 333

Jonathan Dean Swift, Chains and graphs of Ostrom planes . . . . . . . . . . . 353

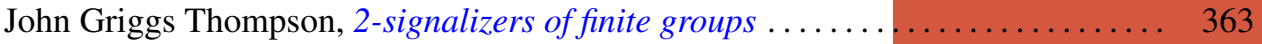

Harold Widom, On the spectrum of a Toeplitz operator . . . . . . . . . . . . . 365 